\title{
Comparative Efficacy of Resin Infiltrant and Two Remineralizing Agents on Demineralized Enamel: An In Vitro Study
}

\author{
Kingston Chellapandian ${ }^{1}$, Tripuravaram VK Reddy ${ }^{2}$, Dhanasekaran Sihivahanan ${ }^{3}$, Ashwin Ravichandran ${ }^{4}$, Sujana Praveen ${ }^{5}$
}

\begin{abstract}
Aim:To compare and evaluate the caries preventive effectiveness of resin infiltrant (ICON), casein phosphopeptide-amorphous calcium phosphate (CPP-ACP) (GC Tooth Mousse), and nanohydroxyapatite (Aclaim) on incipient enamel lesions.

Materials and methods: A total of 60 human maxillary incisors extracted for periodontal reasons were included in this study. The sectioning was done at the middle third region of the crown for the 60 samples with approximate dimensions of $5 \times 5 \times 5 \mathrm{~mm}$ ). In order to create the artificial enamel lesions, the samples were demineralized by placing in a beaker containing the prepared demineralizing solution for 14 days. The study samples were then divided into four groups that are resin infiltrant (group I), CPP-ACP (group II), nanohydroxyapatite (group III), and control (group IV) with 15 enamel samples in each group. The caries preventive efficacy of each group was evaluated using a confocal laser scanning microscope.

Results: The mean values after demineralization of enamel samples in demineralizing solution are $245 \mu \mathrm{m}$ for resin infiltrant (group I), $246 \mu \mathrm{m}$ for CPP-ACP (group II), $250 \mu \mathrm{m}$ for nanohydroxyapatite (group III), and $247 \mu \mathrm{m}$ for control (group IV). After remineralizing the enamel samples for a period of 30 days, the results are group I (resin infiltrant) $158 \mu \mathrm{m}>$ group II (CPP-ACP) $28.8 \mu \mathrm{m} \geq$ group III (nanohydroxyapatite) $26.3 \mu \mathrm{m}$. After subjecting it to demineralizing solution again for 14 days, the amount of material that was resistant to acid attack was group I (resin infiltrant) $114 \mu \mathrm{m}(72 \%)>$ group III (CPP-ACP) $16.4 \mu \mathrm{m}$ (57\%) $\geq$ group III (nanohydroxyapatite) $13.8 \mu \mathrm{m}$ (50\%). The untreated control group showed increased progression of lesion and least resistance to acid challenge.

Conclusion: Based on the results from this in vitro study, it can be concluded that when compared to the two remineralizing agents the resin infiltrant showed better caries preventive effectiveness.

Clinical significance: Resin infiltrants have a favorable penetration potential in subsurface or incipient enamel lesions.

Keywords: Casein phosphopeptide-amorphous calcium phosphate, Confocal laser scanning microscope, Nanohydroxyapatite, Resin infiltrant.

The Journal of Contemporary Dental Practice (2020): 10.5005/jp-journals-10024-2824
\end{abstract}

\section{INTRODUCTION}

White spot lesions are initiated by the pathogenic bacteria that have breached the enamel layer and by the organic acids produced by them. These cause the removal of a certain amount of calcium and phosphate ions that fail to be replaced naturally during the remineralization process. ${ }^{1}$ White spot lesions are commonly reversed by the process of remineralization mainly through the application of fluorides. ${ }^{2}$ Deep enamel lesions show a tendency to remineralize only superficially. Consequently, the arrested lesions show a thick and highly mineralized surface layer $^{3}$ but the underlying lesion body is still porous and the whitish appearance often persists. ${ }^{4}$ The goal of caries management is therefore to stop or arrest the progression of the lesion. But, remineralization brought about by the topical application of fluoride requires multiple treatment sessions and a strict long-term follow-up, which requires strong motivation and cooperation from the patient but is often seen to be difficult to achieve. In addition, the monitoring systems used for assessing the status and progression of the lesions over time are still being studied and are difficult to apply in everyday clinical practice. ${ }^{5}$

A new microinvasive treatment method suggested for the management of white spot lesions is the infiltration of a resin into the lesion. The resin infiltrant prevents the further progression of the initial enamel caries lesion by occluding the microporosities within the lesion as it has a low viscosity. \begin{tabular}{l}
\hline${ }^{1-5}$ Department of Conservative Dentistry and Endodontics, SRM \\
Kattankulathur Dental College, Chengalpattu, Tamil Nadu, India \\
Corresponding Author: Kingston Chellapandian, Department of \\
Conservative Dentistry and Endodontics, SRM Kattankulathur Dental \\
College, Chengalpattu, Tamil Nadu, India, Phone: +91 8939359275, \\
e-mail: kingstonsmiles@gmail.com
\end{tabular}

How to cite this article: Chellapandian K, Reddy TVK, Sihivahanan D, et al. Comparative Efficacy of Resin Infiltrant and Two Remineralizing Agents on Demineralized Enamel: An In Vitro Study. J Contemp Dent Pract 2020;21(7):792-797.

Source of support: Nil

Conflict of interest: None

Remineralization of enamel subsurface lesions has been studied widely both in vitro and in situ as well as in numerous clinical studies. ${ }^{6}$ One such system that has been developed uses casein phosphopeptide (CPP) in order to stabilize the calcium and phosphate ions at higher concentrations and to form an amorphous nanocomplex, namely casein phosphopeptide-amorphous calcium phosphate (CPP-ACP). ${ }^{7}$

In the current practice, nanohydroxyapatite has been widely used an effective anticaries agent mainly because of its unique potential to bring about remineralization. ${ }^{8}$ The size of the calcium phosphate crystal also plays an important role in the formation 
of hard tissues and also has a significant impact on its intrinsic properties, solubility, and biocompatibility. ${ }^{9}$

Confocal microscopy is a useful tool to study the infiltration of low-viscosity resins (infiltrants) into the initial enamel carious lesion. The images obtained are high-resolution optical images with depth selectivity. ${ }^{10}$ Currently, there are no studies available in the literature, which compare the depth of penetration of resin infiltrants to other remineralizing agents like CPP-ACP and nanohydroxyapatite.

Hence, the aim of this study was to determine the caries preventive efficacy of a resin infiltrant (ICON), a CPP-stabilized amorphous calcium phosphate (GC Tooth Mousse), and nanohydroxyapatite (Aclaim) in noncavitated enamel lesions using a confocal laser scanning microscope. ${ }^{1}$

\section{Materials and Methods}

The study was conducted at Rajas Dental College and Hospital in Tirunelveli.

\section{Collection of the Teeth}

A total of 60 human maxillary incisors extracted for periodontal reasons were included in this study. Teeth with any visible caries, hypoplastic lesions, and white spot lesions were excluded from this study.

\section{Enamel Sample Preparation}

The teeth were thoroughly cleaned of all debris including calculus and tissue debris. Occupational Safety and Health Administration (OSHA) and Centers for Disease Control and Prevention (CDC) recommendations and guidelines were followed during the collection, storage, sterilization, and handling of the extracted teeth. Then the radicular portions were removed by decoronating the teeth $2 \mathrm{~mm}$ coronal to the cementoenamel junction (CEJ) using a diamond disk (Axis dental, Texas) attached to a slow-speed micromotor straight handpiece rotating at $1500 \mathrm{rpm}$. The sectioning was done at the middle third region of the crown for the 60 samples with approximate dimensions of $5 \times 5 \times 5 \mathrm{~mm}$ and then stored in $10 \%$ formalin at room temperature of $37^{\circ} \mathrm{C}$ and humidity.

\section{Mounting of the Enamel Samples}

A total of 60 enamel slabs were then embedded on an acrylic resin block using a standardized mold having a dimension of $2 \times 1.5 \times 1$ $\mathrm{cm}$, and the embedded blocks were then stored in artificial saliva at $37^{\circ} \mathrm{C}$, which was prepared.

\section{Demineralization of Enamel Samples}

In order to create the artificial enamel lesions, the samples were demineralized by placing in a beaker containing the prepared demineralizing solution (Buskes et al.). ${ }^{11}$ The study samples were then stored for a period of 14 days all the while maintaining a $\mathrm{pH}$ of 5.0 and at $37^{\circ} \mathrm{C}$ temperature within the demineralizing solution. The $\mathrm{pH}$ was checked daily using a $\mathrm{pH}$ meter and any variation in $\mathrm{pH}$ was corrected by adding either glacial acetic acid or potassium hydroxide solution. The study samples were then randomly divided into four groups containing 15 samples each and were stored directly in artificial saliva that was prepared.

\section{Distribution of Samples}

The samples were then divided into four groups each containing 15 samples:

Group I-resin infiltrant (ICON) $(n=15)$

Group II-CPP-ACP (GC Tooth Mousse) $(n=15)$
Group III-nanohydroxyapatite (Aclaim) $(n=15)$

Group IV_control $(n=15)$.

\section{Remineralization of Enamel Samples}

Group I (Resin Infiltrant)

Samples were then subjected to $15 \% \mathrm{HCl}$-etching for 2 minutes, rinsing for 30 seconds, ethanol desiccation for 30 seconds, infiltrant applied and light-cured for 40 seconds.

\section{Group II (CPP-ACP)}

Enamel samples were then brushed with GC Tooth Mousse toothpaste twice daily for 1 minute and stored in artificial saliva for 30 days.

\section{Group III (Nanohydroxyapatite)}

Enamel samples were brushed with Aclaim toothpaste twice daily for 1 minute and stored in artificial saliva for 30 days.

Group IV (Control)

Untreated enamel samples were stored in artificial saliva for 30 days. The samples in all the groups were subjected to demineralizing solution for 14 days.

\section{Evaluation of Penetration}

The infiltrated specimens were then observed using a confocal laser scanning microscope equipped with argon/krypton laser.

\section{Evaluation of Resistance to Acid Challenge}

The study samples were subjected to demineralizing solution again for 14 days to evaluate the depth of the lesion or resistance to acid challenge using a confocal laser scanning microscope.

\section{Statistical Analysis}

Data were analyzed using SPSS version 20.0. Data were statistically analyzed using ANOVA. And the post hoc Bonferroni test was used for comparing intragroups and the Tukey test was used to compare intergroups.

\section{RESULTS}

Table 1 shows comparison of group I (resin infiltrant) after demineralization, remineralization, and second demineralization. The mean value after demineralization of enamel samples in demineralizing solution is $245 \mu \mathrm{m}$, and after infiltrating with the ICON resin infiltrant there was a mean penetration of $158 \mu \mathrm{m}$ (Fig. 1A). After second demineralization for a period of 14 days, there was a $22 \%$ decrease (Fig. $2 \mathrm{~A}$ ) in the amount of the material that was present.

Table 2 shows comparison of group II (GC Tooth Mousse) after demineralization, remineralization, and second demineralization. The mean value after demineralization of enamel samples in demineralizing solution is $246 \mu \mathrm{m}$. After remineralizing the enamel samples for a period of 30 days, there was a surface remineralization of $28 \mu \mathrm{m}$ (Fig. 1B). After second demineralization for a period of 14 days, there was a $48 \%$ decrease (Fig. $2 B$ ) in the amount of the remineralized surface.

Table 3 shows the comparison of group III (Aclaim) after demineralization, remineralization, and second demineralization. The mean value after demineralization of enamel samples in demineralizing solution is $250 \mu \mathrm{m}$. After remineralizing the enamel samples for a period of 30 days, there was a surface remineralization of $26.3 \mu \mathrm{m}$ (Fig. 1C). After second demineralization for a period of 
Table 1: Comparison of group I (resin infiltrant) after demineralization, resin infiltration, and second demineralization

\begin{tabular}{lllllll}
\hline & & & \multicolumn{2}{c}{$95 \%$ confidence interval } & & \\
\cline { 4 - 5 } ICON & Mean & Std. error & Lower bound & Upper bound & p value & Post hoc \\
\hline Demineralization & 245.000 & 22.571 & 193.941 & 296.059 & $<0.001$ & $\begin{array}{l}\text { Demineralization* }>\text { Remineralization* }> \\
\text { Demineralization 2 }\end{array}$ \\
Remineralization & 158.100 & 16.903 & 119.862 & 196.338 & & \\
Demineralization 2 & 114.000 & 13.013 & 84.563 & 143.437 & & \\
\hline
\end{tabular}
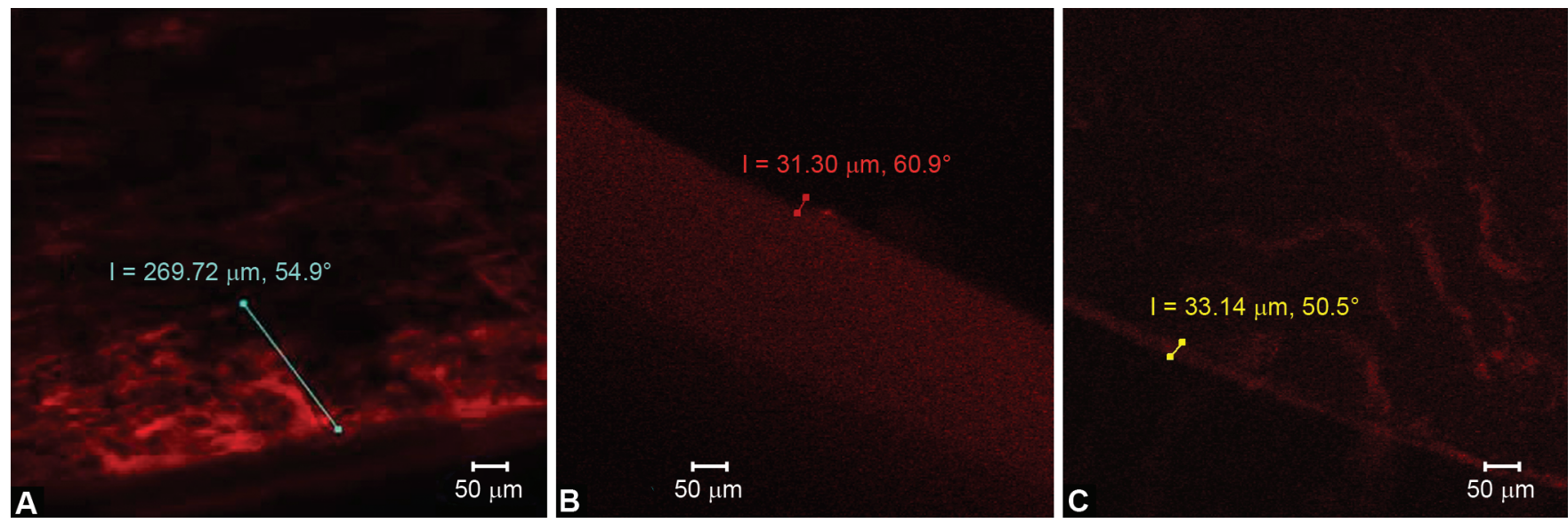

Figs 1 A to C: (A) Penetration of resin infiltrant after demineralization as seen in a confocal laser scanning microscope; (B) Remineralization of CPP-ACP (GC Tooth Mousse) group after demineralization as seen in a confocal laser scanning microscope; (C) Remineralization of the nanohydroxyapatite (Aclaim) group after demineralization as seen in a confocal laser scanning microscope
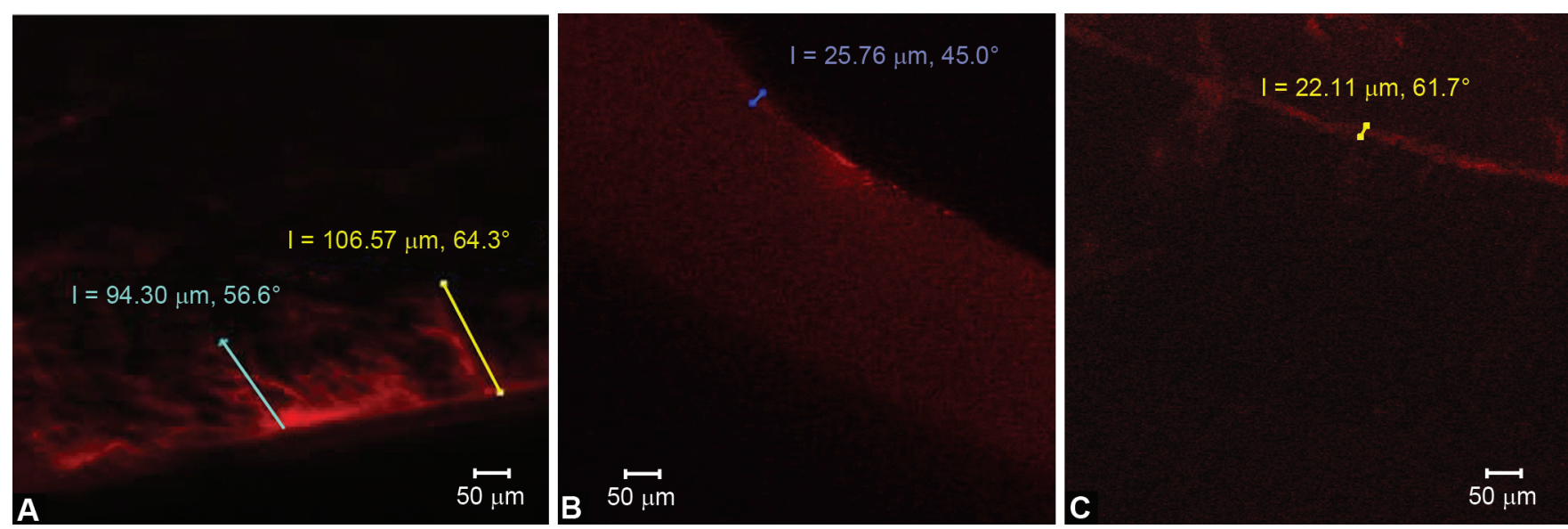

Figs 2A to C: (A) Resin infiltrant (group I) after second demineralization as seen in a confocal laser scanning microscope; (B) CPPACP (GC Tooth Mousse) (group II) after second demineralization as seen in a confocal laser scanning microscope; (C) Nanohydroxyapatite (Aclaim) (group III) after second demineralization as seen in a confocal laser scanning microscope

Table 2: Comparison of group II (GC Tooth Mousse) after demineralization, remineralization, and second demineralization

\begin{tabular}{|c|c|c|c|c|c|c|}
\hline \multirow[b]{2}{*}{ GC } & \multirow[b]{2}{*}{ Mean } & \multirow[b]{2}{*}{ Std. error } & \multicolumn{2}{|c|}{ 95\% confidence interval } & \multirow[b]{2}{*}{$p$ value } & \multirow[b]{2}{*}{ Post hoc } \\
\hline & & & Lower bound & Upper bound & & \\
\hline Demineralization & 246.000 & 23.200 & 193.519 & 298.481 & \multirow[t]{3}{*}{$<0.001$} & \multirow{3}{*}{$\begin{array}{l}\text { Demineralization* }>\text { Remineralization* }> \\
\text { Demineralization } 2\end{array}$} \\
\hline Remineralization & 28.800 & 0.742 & 27.121 & 30.479 & & \\
\hline Demineralization 2 & 16.400 & 0.542 & 15.175 & 17.625 & & \\
\hline
\end{tabular}

14 days, there was a $49 \%$ decrease (Fig. 2C) in the amount of the remineralized surface.

Table 4 compares values for all the groups after demineralization, remineralization, and second demineralization. The mean value after demineralization of enamel samples in demineralizing solution is group III $(250 \mu \mathrm{m})>$ group IV $(246 \mu \mathrm{m})>$ group II $(246$ $\mu \mathrm{m})>$ group I $(245 \mu \mathrm{m})$. After remineralizing the enamel samples for a period of 30 days, there was a surface remineralization, which 
Comparative Efficacy of Resin Infiltrant and Two Remineralizing Agents on Demineralized Enamel

Table 3: Comparison of group III (Aclaim) after demineralization, remineralization, and second demineralization

\begin{tabular}{lcccccl}
\hline & & & \multicolumn{2}{c}{ 95\% confidence interval } & & \\
\cline { 3 - 5 } Aclaim & Mean & Std. error & Lower bound & Upper bound & p value & Post hoc \\
\hline Demineralization & 250.500 & 21.889 & 200.983 & 300.017 & $<0.001$ & Demineralization* $>$ Remineralization* $>$ \\
Remineralization & 26.300 & 0.367 & 25.471 & 27.129 & & Demineralization 2 \\
Demineralization 2 & 13.800 & 0.663 & 12.299 & 15.301 & & \\
\hline
\end{tabular}

Table 4: Intergroup comparison of all the three groups after demineralization, remineralization, and second demineralization

\begin{tabular}{|c|c|c|c|c|c|c|c|c|c|c|}
\hline \multirow[b]{2}{*}{ Group } & & \multirow[b]{2}{*}{$n$} & \multirow[b]{2}{*}{ Mean } & \multirow[b]{2}{*}{ Std. deviation } & \multicolumn{2}{|c|}{ 95\% Confidence interval } & \multirow[b]{2}{*}{ Minimum } & \multirow[b]{2}{*}{ Maximum } & \multirow[b]{2}{*}{$p$ value } & \multirow{2}{*}{$\begin{array}{l}\text { Post hoc } \\
\text { (Tukey test) }\end{array}$} \\
\hline & & & & & Lower bound & Upper bound & & & & \\
\hline \multirow[t]{4}{*}{ Demineralization } & Group I (ICON) & 10 & 245.00 & 71.37538 & 193.9411 & 296.0589 & 150.00 & 370.00 & 0.983 & - \\
\hline & Group II (GC) & 10 & 246.00 & 73.36363 & 193.5188 & 298.4812 & 150.00 & 380.00 & & \\
\hline & Group III (ACC) & 10 & 250.50 & 69.21986 & 200.9831 & 300.0169 & 180.00 & 370.00 & & \\
\hline & Total & 30 & 247.17 & 68.87875 & 221.4469 & 272.8864 & 150.00 & 380.00 & & \\
\hline \multirow[t]{4}{*}{ Remineralization } & Group I (ICON) & 10 & 158.10 & 53.45289 & 119.8621 & 196.3379 & 94.00 & 269.00 & $<0.001$ & $\operatorname{ICON}{ }^{*}>$ \\
\hline & Group II (GC) & 10 & 28.80 & 2.34758 & 27.1206 & 30.4794 & 25.00 & 31.00 & & $(\mathrm{GC}=\mathrm{ACC})$ \\
\hline & Group III (ACC) & 10 & 26.30 & 1.15950 & 25.4705 & 27.1295 & 25.00 & 28.00 & & \\
\hline & Total & 30 & 71.06 & 69.33921 & 45.1750 & 96.9584 & 25.00 & 269.00 & & \\
\hline \multirow[t]{4}{*}{ Demineralization 2} & Group I (ICON) & 10 & 114.00 & 41.15013 & 84.5630 & 143.4370 & 60.00 & 180.00 & $<0.001$ & $\mathrm{ICON}^{*}>$ \\
\hline & Group II (GC) & 10 & 16.40 & 1.71270 & 15.1748 & 17.6252 & 14.00 & 18.00 & & \\
\hline & Group III (ACC) & 10 & 13.80 & 2.09762 & 12.2995 & 15.3005 & 12.00 & 18.00 & & \\
\hline & Total & 30 & 48.06 & 52.70211 & 28.3874 & 67.7460 & 12.00 & 180.00 & & \\
\hline
\end{tabular}

is greater for group I $(158 \mu \mathrm{m})$ (Fig. 1A) > group II $(28.8 \mu \mathrm{m})>$ group III $(26.3 \mu \mathrm{m})$. After second demineralization for a period of 14 days, there was a group III (49\%) decrease > group II (48\%) > group I (22\%) (Fig. 2B) decrease in the amount of the remineralized surface.

\section{Discussion}

Carious lesions formed on the enamel surface are unique in that the enamel is both acellular and avascular. Thus, in contrast to other tissues, the enamel cannot heal by the cellular repair mechanism. ${ }^{12}$ It is now a well-established fact that the formation of incipient enamel white spot lesions is a reversible process, where periods of demineralization alternate with periods of remineralization. ${ }^{13} \mathrm{~A}$ favorable environment in the oral cavity leads to remineralization and helps in the repair of the carious lesion. ${ }^{14}$ In early carious lesions, the enamel surface remains relatively unaltered, whereas the mineral loss associated with the underlying lesion body can be substantial. Clinically, such enamel lesions appear as whitish discolored areas commonly referred to as white spot lesions. ${ }^{15}$

In the present study, to create the artificial enamel lesions on the enamel samples, the specimens were exposed to demineralizing solution composed of $6 \mu \mathrm{m}$ methylhydroxydiphosphonate, $3 \mathrm{mM}$ $\mathrm{CaCl}_{2} .2 \mathrm{H}_{2} \mathrm{O}, 3 \mathrm{mM} \mathrm{KH}_{2} \mathrm{PO}_{4}, 50 \mathrm{Mm}$ acetic acid, and traces of thymol for 14 days $\left(\mathrm{pH} 5.0\right.$ at $37^{\circ} \mathrm{C}$ ) (Buskes et al. ${ }^{11}$ ). The $\mathrm{pH}$ was checked daily with the help of a pH meter and when necessary it was corrected by adding small amounts of either glacial acetic acid or potassium hydroxide solution and $\mathrm{pH}$ was maintained at 5.5. The mean lesion depth after demineralizing the enamel samples for all the four groups was $247 \mu \mathrm{m}$, which is in accordance with the results of previous studies by Meyer Lueckal et al. ${ }^{16}$ who reported the mean lesion depth was $357 \mu \mathrm{m}$ and Mueller et al. ${ }^{17}$ who reported the mean lesion depth was $237 \mu \mathrm{m}$.
In the present study, a confocal laser scanning microscope was used to visualize the penetration of the material. In a study by Pioch et al., ${ }^{10}$ it was proved that a confocal laser scanning microscope had the following advantages of nondestructive examination, since the layer visualized can be situated up to $100 \mu \mathrm{m}$ below the surface. Moreover, drying of the samples, which is required for conventional scanning electron microscopy or transmission electron microscopy, is not necessary leading to decreased risk of shrinkage or other artifacts. $^{10}$

In the present study, acid conditioning with Icon ( 2 minute with $15 \%$ hydrochloric acid) could have led to deeper resin penetration than etching with $37 \%$ phosphoric acid gel (Paris et al. ${ }^{18}$ ). It could be argued that removal of the surface layer by $15 \% \mathrm{HCl}$ could additionally weaken the lesion structure. According to a study done by Meyer-Lueckel et al., ${ }^{16}$ it was proved that no cavitation occurred after acid etching even if the complete surface layer was completely eroded and subsequent resin infiltration could ensure restrengthening of the lesion structure.

In the present study, the Icon-dry (which contains 99\% ethanol) was applied for 30 seconds prior to application of the infiltrant. In a study by Paris et al., ${ }^{19}$ it was proved that addition of ethanol is associated with the higher penetration coefficient by decreasing the viscosity and contact angle; hence, they can be used as promising tools for rapid penetration. It was also proved that mixtures containing large amounts of HEMA, TEGDMA, and ethanol are associated with higher penetration coefficients and satisfactory hardening; therefore, they might be promising tools for rapid caries penetration.

In the present study, the mean penetration of the treated enamel samples for the resin infiltrant group (group I), which was observed using a confocal laser scanning microscope, is $158 \mu \mathrm{m}$ (Table 1 and Figs 3 and $1 \mathrm{~A}$ ). In previous studies by Paris et al. ${ }^{20}$ and 


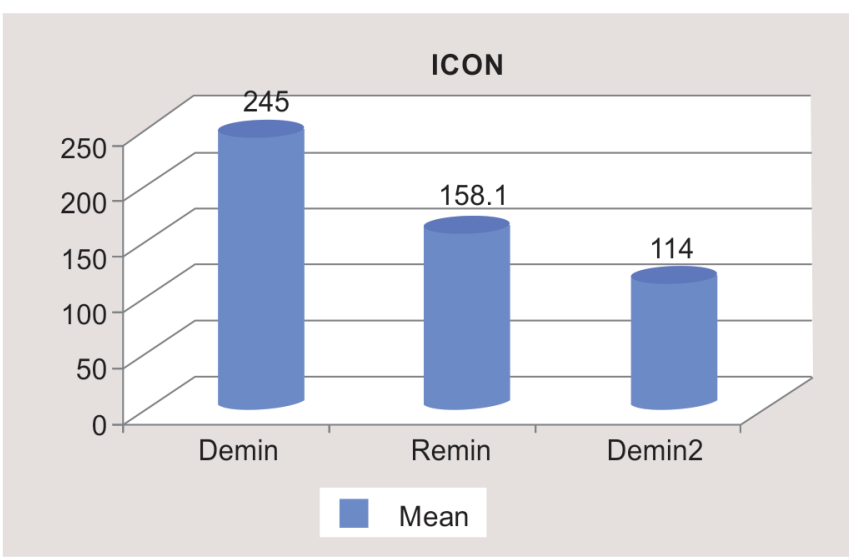

Fig. 3: Comparison of group I (resin infiltrant) after demineralization, resin infiltration, and second demineralization

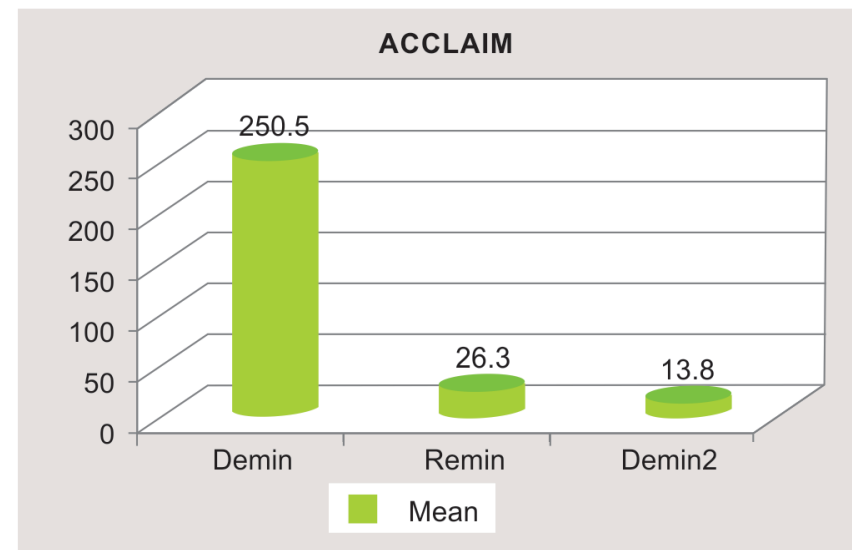

Fig. 5: Comparison of group III (Aclaim) after demineralization, remineralization, and second demineralization

Meyer-Lueckel et al., ${ }^{21}$ the mean penetrations of resin infiltrants were 58 and $104 \mu \mathrm{m}$, respectively.

In the present study, the remineralized areas for group II (CCPACP) and group III (nanohydroxyapatite) observed in a confocal laser scanning microscope are $28.8 \mu \mathrm{m}$ (Table 2 and Figs 4 and 1B) and $26.3 \mu \mathrm{m}$ (Table 3 and Figs 5 and 1C), respectively. In the present study, paste-type formulation of CPP-ACP was used. The remineralization process of CPP-ACP involves diffusion of calcium and phosphate ions through the protein-/water-filled pores of the caries surface enamel into the body of the enamel lesion. Once in the body of the enamel lesion, these calcium and phosphate species increase the activities of $\mathrm{Ca}^{2+}$ and $\mathrm{PO}_{4}{ }^{3-}$, thereby increasing the degree of saturation with respect to hydroxyapatite. ${ }^{21}$

After second demineralization for a period of 14 days, the amount of remaining resin infiltrant that was resistant to acid attack was $114 \mu \mathrm{m}$ (72\%) (Table 1) (Figs 3 and 2A), amount remaining for CPP-ACP was $16.4 \mu \mathrm{m}$ (Table 2 and Figs $2 \mathrm{~B}$ and 4) (57\%), for nanohydroxyapatite was $13.8 \mu \mathrm{m}$ (Table 3 and Figs $2 \mathrm{C}$ and 5) (50\%), increased progression of depth of lesion, and no resistance for the untreated control group (Fig. 6).

There are few limitations; the number of clinical trials was found to be small. Therefore, more high-quality research is needed to evaluate to what extent there is a difference in the effectiveness of infiltrated lesions and sites to be preserved by oral hygiene/fluoride programs. The carryover effect of fluoride applications cannot be

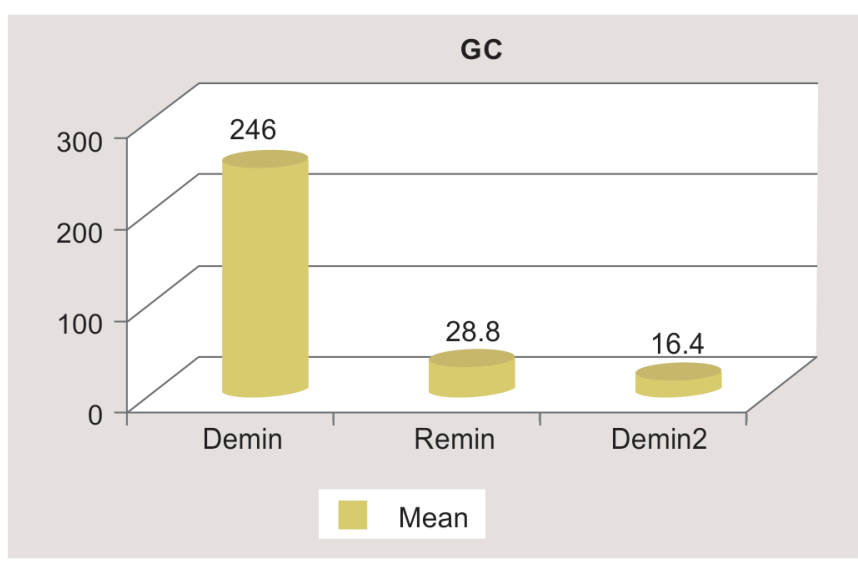

Fig. 4: Comparison of group II (GC Tooth Mousse) after demineralization, remineralization, and second demineralization

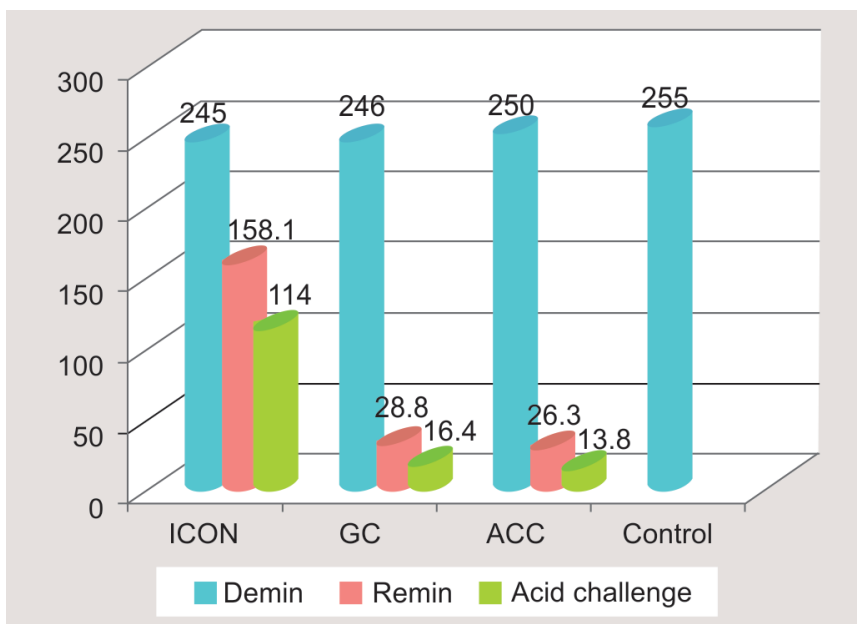

Fig. 6: Intergroup comparison of all the three groups after demineralization, remineralization, and second demineralization

totally ruled out and randomized controlled trials with a parallel group design seem mandatory. Moreover, there is need to study the reasons for lesion progress, in vitro and in vivo; mechanical, chemical, and biologic behaviors of materials used as infiltrants, with variations of application procedures (repeated application after different time intervals, possible needs for reinfiltration regimens within preventive-oriented recalls), are considered fields of major interest. Calcium phosphate stabilized by CPP has shown in this study to remineralize enamel subsurface lesions only superficially. Nanohydroxyapatite has a good potential for remineralizing initial enamel caries lesions. In this study, it has showed to remineralize artificial incipient caries lesions superficially.

\section{Conclusion}

Based on the results of this in vitro study, it can be concluded that the resin infiltrant (ICON) showed higher caries inhibition potential than two remineralizing agents, CPP-ACP (GC Tooth Mousse) and nanohydroxyapatite (Aclaim). In addition, the resin infiltrant showed superior acid resistance when subjecting it to demineralizing solution compared to remineralizng agents. The resin infiltrant has a promising role in the management of early enamel carious lesion because of its penetration into the 
demineralized enamel. The resin infiltrant can be used as an alternative microinvasive approach.

\section{References}

1. Mattousch TJ, Van der Veen MH, Zenntner A. Caries lesions after orthodontic treatment followed by quantitative light induced fluorescence. A 2 year follow up. Eur J Oral Sci 2004;29(3):294-298. DOI: 10.1093/ejo/cjm008.

2. Ellwood R, Fejerskov O, Cury JA, et al. Fluorides in caries control Fejerskov O, Kidd E. Dental caries. The Disease and its clinical Management. Oxford: Blackwell Munksgaard; 2008. 287-327.

3. Angmar-Mansson B, ten Cate JM. Light - induced fluorescence studies on dehydration of incipient enamel lesions. Caries Res 2002;36(1):25-30. DOI: 10.1159/000057586.

4. Ardu S, Castioni NV, Benbachir N, et al. Minimally invasive treatment of white spot enamel lesions. Quintessence Int 2007;38(8):633-636.

5. Lasfargues JJ, Bonte $\mathrm{E}$, Guerrieri $\mathrm{A}$, et al. Minimal intervention dentistry: part 6 . caries inhibition by resin infiltration. BDJ 2013;214(2):53-59. DOI: 10.1038/sj.bdj.2013.54.

6. Cochrane NJ, Saranathan S, Cai F, et al. Enamel subsurface lesion remineralization with caseinphosphopeptide stabilized solutions of calcium, phosphate and fluoride. Caries Res 2008;42(2):88-97. DOI: 10.1159/000113161.

7. Reynolds EC. Anticariogenic complexes of amorphous calcium phosphate stabilized by casein phosphopeptides: a review. Spec Care Dentist 1998;18(1):8-16. DOI: 10.1111/j.1754-4505.1998.tb01353.x.

8. Huang $S$, Gao S, Cheng $L$, et al. Remineralization potential of nanohydroxyapatite on initial enamel lesions: an in vitro study. Caries Res 2011;45(5):460-468. DOI: 10.1159/000331207.

9. Balasundaram G, Sato M, Webster TJ. Using hydroxyapatite nanoparticles and decreased crystallinity to promote osteoblast adhesion similar to functionalizing with RGD. Biomater 2006;27(14):2798-2805. DOI: 10.1016/j.biomaterials.2005.12.008.

10. Pioch T, D'Souza PD, Staehle HJ. Resin-dentin interface studied by SEM and CLSM. Microscopy Analysis 1996;42(1):15-16.
11. Buskes JA, Christoffersen J, Arends J. Lesion formation and lesion remineralization in enamel under constant composition conditions. A new technique with applications. Caries Res 1985;19(6):490-496. DOI: $10.1159 / 000260887$.

12. Zero DT. Dental caries process. Dent Clin North Am 1999;43(4): 635-636.

13. Silverstone LM. Remineralization phenomena. Caries Res 1977;11(Suppl. 1):59-79. DOI: 10.1159/000260296.

14. Pearce El, Moore AJ. Remineralization of softened bovine enamel following treatment of overlying plaque with a mineral-enriching solution. J Dent Res 1985;64(3):416-421. DOI: 10.1177/00220345850640030401.

15. Silverstone LM. Structure of carious enamel, including the early lesion. Oral Sci Rev 1973;3:100-160.

16. Meyer-Lueckel $\mathrm{H}$, Paris $\mathrm{S}$. Improved resin infiltration of natural caries lesions. J Dent Res 2008;87(12):1112-1116. DOI: 10.1177/154405910808701201.

17. Mueller J, Meyer-Lueckel H, Paris S, et al. Inhibition of lesion progression by the penetration of resins in vitro: influence of the application procedure. Oper Dent 2006;31(3):338-345. DOI: 10.2341/05-39.

18. Paris $\mathrm{S}$, Meyer-Lueckel $\mathrm{H}$, Cölfen $\mathrm{H}$, et al. Penetration coefficients of commercially available and experimental composites intended to infiltrate enamel carious lesions. Dent Mater 2007;23(6):742-748. DOI: 10.1016/j.dental.2006.06.029.

19. Paris S, Meyer-Lueckel H, Cölfen $\mathrm{H}$, et al. Resin infiltration of artificial enamel caries lesions with experimental light curing resins. Dent Mater J 2007;26(4):582-588. DOI: 10.4012/dmj.26.582.

20. Paris $S$, Meyer-Lueckel $H$, Kielbassa AM. Resin infiltration of natural caries lesions. J Dent Res 2007;86(7):662-666. DOI: $10.1177 / 154405910708600715$.

21. Meyer-Lueckel H, Paris S, Mueller J, et al. Influence of the application time on the penetration of different dental adhesives and a fissure sealant into artificial subsurface lesions in bovine enamel. Dent Mater 2006;22(1):22-28. DOI: 10.1016/j.dental.2005.03.005. 